\title{
Effects of Friction Stir Welding Parameters on Microstructures and Mechanical Properties of Brass Joints
}

\author{
G. M. Xie ${ }^{1,2, *}$ Z. Y. $\mathrm{Ma}^{2, *}$ and L. Geng ${ }^{1}$ \\ ${ }^{1}$ School of Materials Science and Engineering, Harbin Institute of Technology, Harbin 150001, P.R.China \\ ${ }^{2}$ Shenyang National Laboratory for Materials Science, Institute of Metal Research, Chinese Academy of Sciences, \\ Shenyang 110016, P.R.China
}

$5 \mathrm{~mm}$ thick brass plates were successfully friction stir welded at the tool rotation rates from 400 to 1000 rpm for a constant traverse speed of $100 \mathrm{~mm} / \mathrm{min}$. The nugget zone (NZ) consisted of the incompletely and completely-recrystallized regions. With increasing rotation rates, the fraction of the non-recrystallized grains decreased and the size of the recrystallized grains increased. The hardness values in the NZs were higher than those in the parent material (PM). Increasing the rotation rate did not exert a noticeable effect on the tensile and yield strengths of the welds, but increased the elongation. The tensile and yield strengths of the welds reached up to $~ 99$ and $80 \%$ of the PM, respectively. The fracture occurred in the heat affected zone that had the lowest hardness. [doi:10.2320/matertrans.MRP2008089]

(Received March 17, 2008; Accepted April 23, 2008; Published June 11, 2008)

Keywords: friction stir welding, brass, recrystallization, microstructure, mechanical properties

\section{Introduction}

Brass (Cu-Zn alloy) exhibits higher plasticity, strength, hardness and corrosion resistance than pure copper, ${ }^{1)}$ therefore, it is widely applied as structural materials in industries. For the brass, the conventional fusion welding has some obvious limitations. During the fusion welding, the evaporation and melting loss of a large amount of $\mathrm{Zn}$ element resulted in the failure of the welded joint due to lower steam point of $\mathrm{Zn}\left(907^{\circ} \mathrm{C}\right) .^{1)}$

Friction stir welding (FSW), invented by The Welding Institute of the UK in $1991,{ }^{2)}$ is a solid joining technique, therefore, welding defects in the conventional fusion welds were not observed in the FSW joints. ${ }^{3)}$ While the research and applications of FSW have mainly focused on the aluminum and magnesium alloys, ${ }^{4,5)}$ the investigations into the FSW of pure copper are relatively limited. ${ }^{6-8)}$ This is attributed to the high melting point and good thermal conductibility of pure copper, which requires a higher heat input during FSW to achieve a defect-free weld. Compared to pure copper, dual-phase brass contains a great amount of $\beta^{\prime}$ ( $\mathrm{CuZn}$ compound) phase that exhibits higher hardness and poorer deformation ability than $\alpha$ phase. The $\beta^{\prime}$ phase could exert a significant effect on the plastic flow and recrystallization process of the weld during FSW. However, the studies on FSW brass is quite limited.9)

Park et al. ${ }^{9)}$ reported that $2 \mathrm{~mm}$ thick $60 \% \mathrm{Cu}-40 \% \mathrm{Zn}$ (60/40 brass) alloy sheets were successfully friction stir welded under a wide range of FSW parameters and a homogeneous recrystallized structure in the nugget zone (NZ) was observed. This seemingly indicates that brittle and hard $\beta^{\prime}$ phase in the brass did not affect the material flow and recrystallization behaviors. However, it should be pointed out that the plate thickness of $2 \mathrm{~mm}$ used in Ref. 9) was no typical for most FSW operations. For such a thin 60/40 brass plate, the plastic deformation was relatively homogeneous in

*Corresponding author, E-mail: gmxiehit@yahoo.com (G.M. Xie) and zyma@imr.ac.cn (Z.Y. Ma) the NZ due to the dominant effect of the tool shoulder. Furthermore, the number fraction of the $\beta^{\prime}$ phase $(\sim 16 \%)$ in Ref. 9) is relatively low. Therefore, a further FSW investigation on thicker plate of brass with higher fraction of $\beta^{\prime}$ phase is needed to understand the microstructural evolution of brass during FSW.

In this work, $5 \mathrm{~mm}$ thick $62 / 38$ brass plates were subjected to FSW at various rotation rates, and the microstructural evolution and mechanical properties of FSW brass joints were examined.

\section{Experimental Procedure}

$5 \mathrm{~mm}$ thick commercial brass plate under $1 / 2 \mathrm{H}$ condition was used in this study. The chemical compositions were $\mathrm{Cu}$ $38 \mathrm{Zn}-0.15 \mathrm{Fe}-0.08 \mathrm{~Pb}-0.5 \mathrm{Ni}$ (mass $\%$ ). FSW was conducted at a constant traverse speed of $100 \mathrm{~mm} / \mathrm{min}$ with the tool rotation rates of 400, 600, 800 and $1000 \mathrm{rpm}$, respectively. A tool with a shoulder $18 \mathrm{~mm}$ in diameter and a cylindrical threaded pin $6 \mathrm{~mm}$ in diameter and $4.7 \mathrm{~mm}$ in length was used. The tilt angle for all welds was maintained at $2.5^{\circ}$ and the plunged depth was controlled at $\sim 0.2 \mathrm{~mm}$.

The FSW samples were cross-sectioned perpendicular to the welding direction, polished and then etched with a solution of $100 \mathrm{ml}$ distilled water, $15 \mathrm{ml}$ hydrochloric acid, and $2.5 \mathrm{~g}$ iron (iii) chloride. Microstructural features were characterized by optical microscopy (OM). The microhardness of the welds was measured along the mid-thickness of the plates with $500 \mathrm{~g}$ load for $10 \mathrm{~s}$ by LECO-LM247AT type Vickers-hardness machine. The transverse tensile specimens with a gauge length of $40 \mathrm{~mm}$ and a width of $10 \mathrm{~mm}$ were machined perpendicular to the FSW direction. The tensile test was carried out using a Zwick-Roll-type testing machine at a strain rate of $4.2 \times 10^{-4} \mathrm{~s}^{-1}$.

\section{Results and Discussion}

Figure 1 shows the cross-sectional macrographs of the FSW brass joints under different rotation rates. Defect-free 

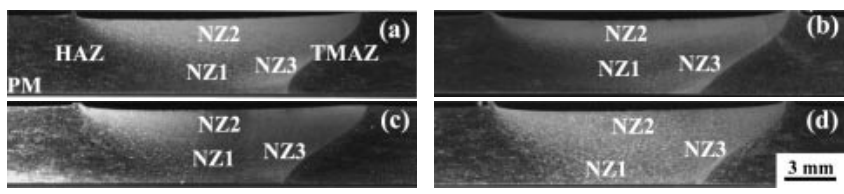

Fig. 1 Macrographs of FSW brass joints at different rotation rates: (a) $400 \mathrm{rpm}$, (b) $600 \mathrm{rpm}$, (c) $800 \mathrm{rpm}$ and (d) $1000 \mathrm{rpm}$ (The advancing side is on the right).
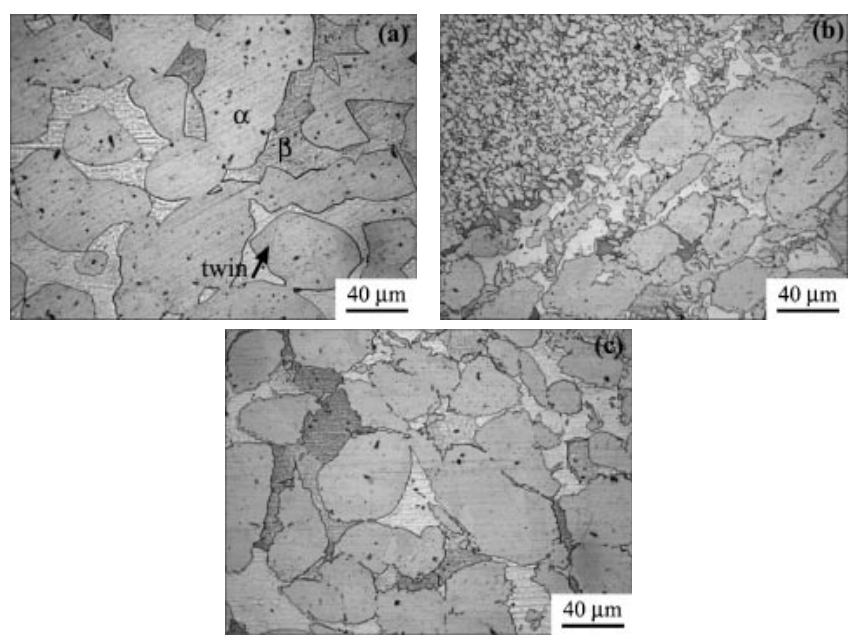

Fig. 2 Microstructure of brass: (a) PM, (b) TMAZ at $600 \mathrm{rpm}$ and (c) HAZ at $600 \mathrm{rpm}$.

welds were achieved under a wide rotation rate range of 400 to $1000 \mathrm{rpm}$ for a constant traverse speed of $100 \mathrm{~mm} / \mathrm{min}$. Similar to those reported by Park et al. ${ }^{9)}$ the typical basinshaped NZs were observed at various rotation rates, and the advancing side of the welds exhibited clear boundaries between the NZs and thermo-mechanically affected zones (TMAZ).

The parent material (PM) was characterized by coarse $\alpha$ phase and $\beta^{\prime}$ phase in between with the smooth grain boundaries and number of twins in the $\alpha$ phase (Fig. 2(a)). In the TMAZ, the elongated $\alpha$ and $\beta^{\prime}$ phases were distributed along the boundary of the NZ (Fig. 2(b)). The microstructures of the heat-affected zone (HAZ) were characterized by serrated grain boundaries (Fig. 2(c)). This is attributed to the transformation of $\beta^{\prime}$ phase to $\alpha$ phase in brass due to the heat effect of FSW. It is noted that the HAZs at the tool rotation rate of 400 to $1000 \mathrm{rpm}$ exhibited similar microstructures (Figs. 2(c) and 3). Therefore, although increasing the rotation rates increased the FSW heat input, the microstructure of the HAZs of the FSW brass was not significantly changed in this study under the investigated rotation rates.

For the FSW joints of aluminum alloys, magnesium alloys, and pure copper, usually, a relatively homogeneous microstructure was achieved throughout the NZ. ${ }^{4-8)}$ The heterogonous NZs were obtained in the FSW brass joints (Fig. 4). The NZ can be divided to three parts (NZ1, NZ2 and NZ3), as shown in Fig. 1. The NZ1 was characterized by coarse non-recrystallized deformed grains and fine recrystallized grains, indicating that the dynamic recrystallization did not occur completely in the NZ1 during FSW. The incomplete
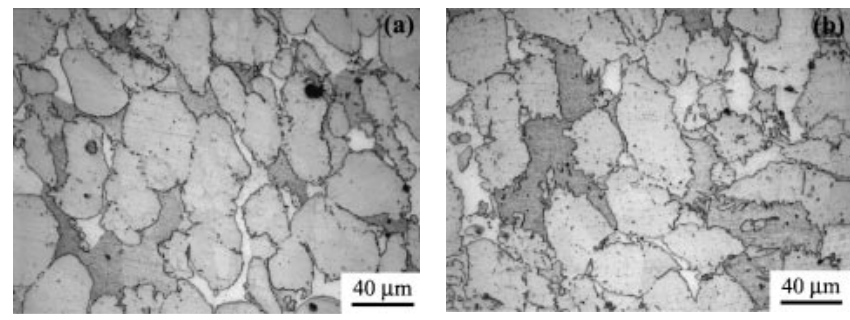

Fig. 3 Microstructure of brass: (a) HAZ at $400 \mathrm{rpm}$ and (b) HAZ at $1000 \mathrm{rpm}$.
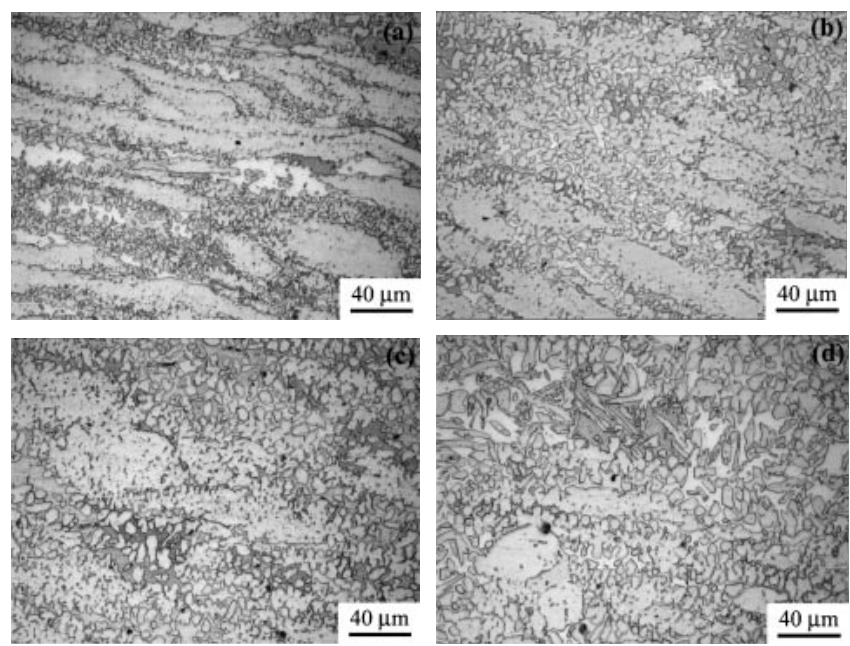

Fig. 4 Microstructure of NZ1 of FSW brass joints at (a) $400 \mathrm{rpm}$, (b) $600 \mathrm{rpm}$, (c) $800 \mathrm{rpm}$, and (d) $1000 \mathrm{rpm}$.

recrystallization in the present FSW 62/38 brass might be associated with the existence of a great amount of the $\beta^{\prime}$-phase $(27 \%)$ that would inhibit plastic deformation and the dynamic recrystallization. Detailed microstructural examinations and discussion about the incomplete recrystallization in the FSW brass will be elsewhere presented. With increasing the rotation rate, the increased heat input and enhanced plastic deformation resulted in the decrease in the fraction of the non-recrystallized grains and the increase in both the fraction and size of the recrystallized grains in the NZ1 (Fig. 4). However, the heterogonous microstructure of the $\mathrm{NZ}$ was not eliminated even at a higher rotation rate of $1000 \mathrm{rpm}$.

Both NZ2 and NZ3 consisted of fine fully-recrystallized grains and there was not obvious difference between two zones for all tool rotation rates. Therefore, the microstructure of the NZ3 was not shown in the present study. The remarkably refined microstructure in the NZ2 was attributed to the occurrence of complete dynamic recrystallization (Fig. 5). With increasing the rotation rate, the grain size of the NZ2 significantly increased. This is attributed to the increased heat input that resulted in the coarsening of the recrystallized grains. Similarly, Park et al. reported that the grain size in the NZ of the FSW 60/40 brass increased with increasing the rotation rate. ${ }^{9)}$ However, different from the report by Park et al., ${ }^{9)}$ the NZs of $5 \mathrm{~mm}$ thick FSW $62 / 38$ brass plates at various rotation rates are inhomogeneous. 

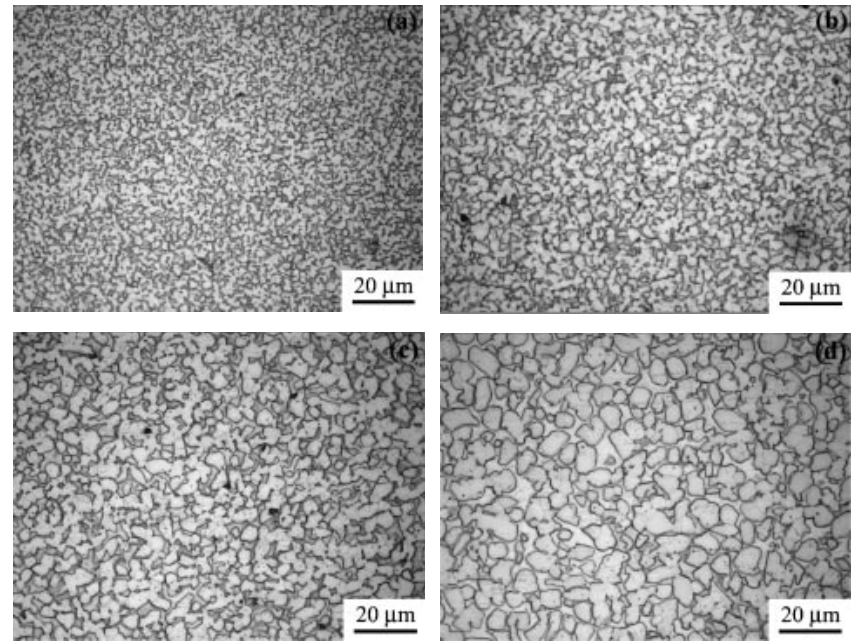

Fig. 5 Microstructure of NZ2 of FSW brass joints at (a) $400 \mathrm{rpm}$, (b) $600 \mathrm{rpm}$, (c) $800 \mathrm{rpm}$ and (d) $1000 \mathrm{rpm}$.

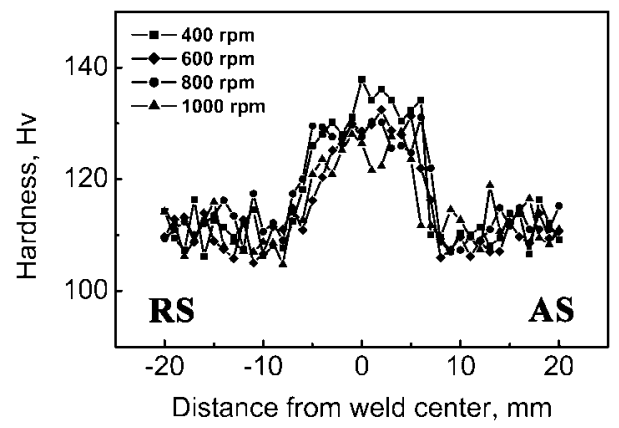

Fig. 6 Hardness profiles in cross-sections of FSW brass joints at different rotation rates (RS and AS are retreating side and advancing side, respectively).

Figure 6 shows the Vicker's hardness profiles along the centerline on the cross-section of the FSW brass joints at different rotation rates. Following observations can be made. First, the lowest hardness zones that correspond to the HAZs (Figs. 2(c) and 3) were observed. This is attributed to significant annealing softening resulting from FSW thermal cycle. Therefore, the HAZ was the softest region for all the FSW brass joints. However, for $2 \mathrm{~mm}$ thick FSW brass joints, no observation of the lowest hardness zone was made in the hardness profiles. ${ }^{9)}$ This might be attributed to very fast heat dissipation rate in the brass sheet. Second, the hardness of the NZ was significantly higher than that of the PM. The as-received brass PM in this study was in $1 / 2 \mathrm{H}$ condition. Therefore, the FSW produced two competitive factors influencing the hardness of the NZ. While the FSW resulted in remarkable annealing softening, thereby reducing the hardness of the NZ, the significant grain refinement increased the hardness of the NZ. At a wide rotation rate range of 400 to $1000 \mathrm{rpm}$, the grain refinement was dominant, so the hardness of the NZs was higher than that of the PM. Third, the hardness profile of the NZ at $400 \mathrm{rpm}$ is quite inhomogeneous, and the hardness values of the NZ on the advancing side are higher than those on the retreating side. This is attributed to finer and more uniform grain

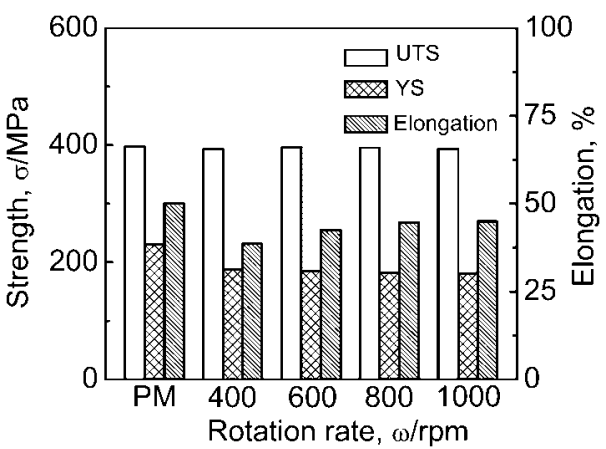

Fig. 7 Transverse tensile properties of PM and FSW brass joints at different rotation rates.

microstructure on the advancing side as discussed above. Fourth, the hardness values of the NZ on the advancing side appear to increase with decreasing the rotation rate. This is attributed to the decrease of the recrystallized grains on the advancing side of the NZ with decreasing the rotation rate. Fifth, the hardness values of the HAZs at different rotation rates are similar. This is attributed to the similar microstructures in the HAZs at different rotation rates (Figs. 2(c) and 3).

Figure 7 shows the mechanical properties of the PM and the FSW brass joints at various rotation rates. It is noted that while the ultimate tensile strengths (UTS) of the welds at various rotation rates are equivalent to that of the PM, the yield strength (YS) and elongation of all the welds are lower than those of the PM. For a constant traverse speed of $100 \mathrm{~mm} / \mathrm{min}$, the YS of the welds at $400,600,800$, and $1000 \mathrm{rpm}$ reached $78.8-81.7 \%$ of the PM and nearly did not change with the rotation rate, and elongation increased from $76.8 \%$ to $89.4 \%$ of the PM with increasing the rotation rate from 400 to $1000 \mathrm{rpm}$. The fracture occurred in the HAZ, which is consistent with the lowest hardness zone in the hardness profiles (Fig. 6). Therefore, the strength of the lowest hardness zone represents that of the welded joint. Previously, Park et al. ${ }^{9)}$ reported that the UTS and YS of $2 \mathrm{~mm}$ thick FSW brass joints produced at $1000 \mathrm{rpm}$ were almost the same as those of the PM, and the fracture occurred either in the PM for a lower traverse speed of $500 \mathrm{~mm} / \mathrm{min}$ or in the NZ for higher traverse speeds of $1000-2000 \mathrm{~mm} / \mathrm{min}$. This is attributed to the absence of the HAZ in the FSW brass sheets. Clearly, the existence of the HAZ in the present FSW brass joints decreases the YS of the weld. This indicates that the plate thickness exerted a significant effect on the microstructure and mechanical properties of the FSW brass joints.

\section{Conclusions}

Under the wide rotation rates of 400 to $1000 \mathrm{rpm}$ for a constant traverse speed of $100 \mathrm{~mm} / \mathrm{min}$, sound FSW joints of $5 \mathrm{~mm}$ thick brass plate were achieved with incomplete recrystallization being observed in the NZ. Increasing the rotation rate decreased the fraction of the non-recrystallized grains, but increased the size of the recrystallized grains. The UTS of the FSW brass joints was similar to that of the PM and their YS and elongation were reduced. 
Increasing the rotation rate did not exert a noticeable effect on the UTS and YS of the welds, but increased the elongation. The fracture occurred at the HAZ that had the lowest hardness.

\section{REFERENCES}

1) Welding Handbook (Vol. 2), (China Machine Press, Bejing, 1992), pp. $469-471$

2) W. M. Thomas, E. D. Nicholas, J. C. Needham, M. G. Murch, P.
Templesmith and C. J. Dawes: G. B. Patent Application No. 9125978.8, Dec. (1991).

3) R. S. Mishra and Z. Y. Ma: Mater. Sci. Eng. R50 (2005) 1.

4) J. Q. Su, T. W. Nelson, R. Mishra and M. Mahoney: Acta Mater. 51 (2003) 713.

5) G. M. Xie, Z. Y. Ma, L. Geng and R. S. Chen: Mater. Sci. Eng. A 471 (2007) 63.

6) W. B. Lee and S. B. Jung: Mater. Lett. 58 (2004) 1041.

7) G. M. Xie, Z. Y. Ma and L. Geng: Scripta Mater. 57 (2007) 73.

8) T. Sakthivel and J. Mukhopadhyay: J. Mater. Sci. 42 (2007) 8126.

9) H. S. Park, T. Kimura, T. Murakami, Y. Nagano, K. Nakata and M. Ushio: Mater. Sci. Eng. A371 (2004) 160. 